\title{
Emergency Teaching-Learning Methods (ETLM) during COVID-19: Lessons Learned from Sri Lanka
}

\author{
Ruchira Gangahagedara ${ }^{1}$, Muditha Karunarathna ${ }^{2}$, Wasantha Athukorala ${ }^{2}$, Shyamantha Subasinghe ${ }^{3, *} \mathbb{D}$ \\ and Prabath Ekanayake ${ }^{4}$
}

1 Postgraduate Institute of Humanities and Social Sciences, University of Peradeniya, Peradeniya 20400, Sri Lanka; gangahagedara.ruchira@gmail.com

2 Department of Economics and Statistics, University of Peradeniya, Peradeniya 20400, Sri Lanka; mudithakr@yahoo.com (M.K.); wathukorala@yahoo.com (W.A.)

3 Department of Geography, University of Peradeniya, Peradeniya 20400, Sri Lanka

4 Department of Education, University of Peradeniya, Peradeniya 20400, Sri Lanka; empcse@yahoo.co.uk

* Correspondence: shyamgeo@pdn.ac.lk

check for updates

Citation: Gangahagedara, R.; Karunarathna, M.; Athukorala, W.; Subasinghe, S.; Ekanayake, P. Emergency Teaching-Learning Methods (ETLM) during COVID-19: Lessons Learned from Sri Lanka. Educ. Sci. 2021, 11, 579. https:// doi.org/10.3390/educsci11100579

Academic Editors:

Christos Dimopoulos,

Maria Meletiou-Mavrotheris,

Geroge Boustras and

Evangelos Katsaros

Received: 14 August 2021

Accepted: 20 September 2021

Published: 24 September 2021

Publisher's Note: MDPI stays neutral with regard to jurisdictional claims in published maps and institutional affiliations.

Copyright: (c) 2021 by the authors. Licensee MDPI, Basel, Switzerland. This article is an open access article distributed under the terms and conditions of the Creative Commons Attribution (CC BY) license (https:/ / creativecommons.org/licenses/by/ $4.0 /)$.

\begin{abstract}
Sri Lanka's education system was suddenly shifted from classroom-based free education to online-based distance learning as an emergency teaching and learning method (ETLM) in response to the COVID-19 pandemic lockdown. This study examines how various stakeholders used onlinebased distant learning as an ETLM, and highlights the lessons learned from such a transition in Sri Lanka through a case study of the Kandy education zone (KEZ), in response to the country's COVID19 pandemic lockdown. We obtained the data through a questionnaire survey from 19 schools in KEZ, selecting the teachers, students, and parents as a survey sample. The findings revealed that nearly $64.7 \%$ of teachers used social media for the teaching-learning process (TLP), $27.9 \%$ used standard online teaching platforms, and only $7.4 \%$ used traditional teaching methods during the pandemic lockdown. Additionally, $36.5 \%$ of teachers and $41.2 \%$ of students favored the WhatsApp mobile application for the TLP, while others preferred other applications. However, during the COVID-19 lockdown, most of the less privileged schools in the peripheral areas of the KEZ adopted traditional teaching methods (TTM). The extent of the gap in ETLM adaptation and the driving factors that led to observable discrepancies between privileged and non-privileged schools, even in the urban settings of the KEZ, are also discussed in this study. These findings are significant in terms of educational policy making and management. Overall, this research contributes to understanding the ETLM adaptation of the KEZ by proposing policy directions that policymakers and other higher education authorities in the country should consider in an emergency.
\end{abstract}

Keywords: COVID-19; emergency teaching-learning methods; education; Kandy

\section{Introduction}

The COVID-19 pandemic may be considered as one of the world's most serious education crises to occur in the recent past. According to the United Nations Educational, Scientific and Cultural Organization (UNESCO), during the first wave of the COVID-19 pandemic, over 190 countries implemented nationwide closures, affecting more than $90 \%$ of the world's student population [1]. COVID-19 had a more significant impact on the TLP in developing nations, particularly Asia and Africa, due to a lack of preparedness and infrastructure for emergency learning methods.

A South Asian developing country, Sri Lanka began providing free education in the late 1940s, shortly after gaining independence from British rule in 1948 [2]. Free education in their native language was made available to all people, with a full range of facilities provided in schools around the country to ensure increased education access [3]. Although the government has a free education system, there is still inequality in access to educational facilities and resources [4]. However, as a result of the new normal situation created by 
the COVID-19 scenario, considerable discrepancies in educational access have occurred. In this context, adopting an ETLM as a developing country is crucial [5]. Sri Lanka faces significant difficulties in establishing a learning and teaching environment accessible to all students and teachers, without discrimination, within the free education system [6]. In response to the first wave of the COVID-19 pandemic, all educational institutions in Sri Lanka, including schools and universities, were closed overnight, and switched to online teaching-learning methods through distance learning without any prior training or preparation.

Distance learning is not a new practice in the world's education system. According to the Biblical accounts, St. Paul's proclamation of the gospel via letters to early church groups was a sort of distance education. According to Williams et al. [7], St. Paul's students were responsible for widely disseminating the gospel throughout church groups and followers, and his writings served as a sort of education. The University of London was a pioneer in distance education, beginning in the early 19th century with printed texts and shorthand scripts. In 1840, their first program was run from an English city to Bath. In 1910, the United States established international correspondence schools, enrolling 184,000 students in distance education.

The application of technology to distance education began in the early 20th century, with instructional films being introduced as a form of teaching in 1910. In 1932, the University of Iowa began offering distance-learning courses. Meanwhile, the Department of Education in the United Kingdom started offering radio-based distant education in the mid-1920s. During the post-World War II era, television and radio had a tremendous impact on education [8]. Several educational institutions transmitted their educational programs on television and radio during this era.

Consequently, the University of Wisconsin launched the Articulated Instructional Media Project (AIM). This new teaching-learning platform attempted to provide a complete distance education system, including broadcast media, correspondence, and telephone calls [9]. Meanwhile, the United Kingdom and the rest of the developing and developed worlds introduced a new system known as the "University of the Air", or the Open University concept, delivered entirely online [7]. Later, the internet became the primary medium for facilitating remote or distance learning. According to Olson and Wisher, webbased education promotes more engagement in the TLP when compared to traditional distance classroom settings.

Online education is currently becoming increasingly popular among both teachers and students. Ertmer [10] emphasized the importance of teachers' attitudes and beliefs towards online learning. Swan et al. recommend three factors that can help online courses be more productive [11]. These included the interface's transparency and quality factors, the instructor's interactive nature, and a dynamic TLP with optimal student participation. Most studies have revealed that online education is interactive and innovative, enhancing traditional teaching and homeschooling [12-14]. However, there are both material and nonmaterial obstacles to online education. According to Pelgrum [15], a lack of technologies available in ICT is a material obstacle, and lack of knowledge and skills in ICT is a nonmaterial obstacle.

In Sri Lanka's urban areas, information and communication technology (ICT) has developed dramatically since the 2000s [16]. At the same time, a new digital gap, known as rural-urban dualism, is emerging in rural areas. Later, Sri Lanka established several ICT initiatives, the most notable of which are the "Nanasala" centers [17]. Their overarching goal is to use ICT to bridge the internal digital gap between urban and rural areas [18]. However, the literature indicates that the country's use of online teaching and learning, both in higher education and in schools, is at a primitive level. The current COVID-19 pandemicrelated emergency scenario has improved online teaching-learning in the country.

We used the Kandy Educational Zone (KEZ) as a case study to examine how different stakeholders use online-based distance learning as an ETLM, highlighting the lessons learned from such a rapid shift from classroom-based free education to online-based ETLM. 
Gangawatakoralaya and Pathahewaheta are the two divisions that make up the KEZ. Our survey was conducted in the Gangawatakoralaya division to represent the urban setting of the KEZ, which comprises 60 schools and a total student population of 67,661 (excluding private and international schools). Despite many disparities, our focus area, like other schools in the county, provides traditional classroom-based education. It is designed to bring all students to a common equitable platform, regardless of their different cultural or socio-economic backgrounds, by ensuring the co-values of free education. Due to the lockdown imposed during the country's first wave of COVID-19, schools shifted to continue teaching-learning via online teaching, by adopting ETLMs. A few schools used Microsoft Teams, Google Classroom, and Zoom, among other platforms, to create a standardized online teaching approach. Furthermore, some teachers used informal methods, such as cell phone chats and group calls, while others adhered to the rules of health authorities and used traditional teaching-learning methods.

A review of the previous literature found that various studies have covered various aspects of online or distance learning in Sri Lanka. However, most of the studies did not focus on online distance teaching-learning as an ETLM. This study fills this research gap and provides policy directions that policymakers and other higher education authorities should consider in an emergency.

\section{Materials and Methods}

This study employed a questionnaire survey to collect data during Sri Lanka's lockdown due to COVID-19 from August to September 2020. For data analysis, we used the descriptive statistics method. Primary data for the research were obtained from KEZ students, teachers, and parents. The provincial education department lists all government schools in the KEZ (55 schools). Based on a random selection technique, we selected 19 schools for the study.

Figure 1 shows the KEZ (Gangawatakoralaya), which contains 55 schools, with circular dots representing the schools selected for the survey, and triangular dots representing the rest. The map demonstrates the sample's equal distribution through the KEZ. We selected approximately 10 to 25 samples from each category of secondary-level education. As a result, we decided on a final sample size of 797 people. At the schools, survey questionnaires were provided to participants (teachers, parents, and students), adhering to the rules of health authorities when visiting the schools. However, only 16 schools (out of 19) agreed to participate. As a result, the study's sample size was 351 completed (usable) questionnaires. There were 116 teachers, 102 parents, and 133 students among the 351 responses. The demographic information, ICT training and knowledge, and ETLMs adopted by stakeholders during the COVID-19 pandemic were all included in the questionnaire, which was written in Sinhala and Tamil (the country's native languages). Teachers, students, and parents were given three different questionnaires.

Except for demographic data, we repeated other questions in the questionnaires to triangulate the data and asked attitudinal questions in all three questionnaires to trace technological adoption of a distance TLP. A random sample of students and teachers was selected in the schools, while a different set of students was chosen to send the parent questionnaire. In addition, the Probit regression model was used to identify the factors that determined the ETLMs. 


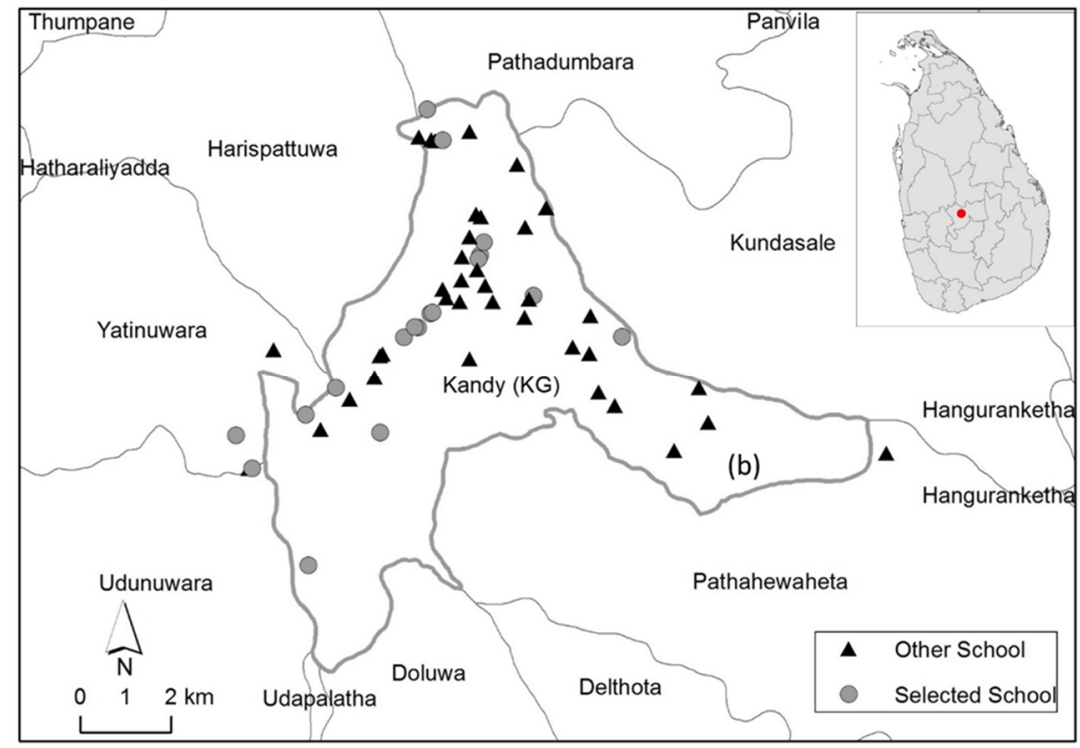

Figure 1. Distribution of the sample.

\section{Results}

Table 1 shows a summary of the demographic data collected from the survey. Accordingly, three categories of schools were reviewed. They are coded as $1 \mathrm{AB}, 1 \mathrm{C}$, and T2, Sri Lanka's school classifications. Classification $1 \mathrm{AB}$ offers education from Grades 1 to 13 or 6 to 13 in all subjects. Classification 1C offers education from Grades 1 to 13 or 6 to 13, and GCE Advanced Levels in Arts and Commerce subjects. T2 offers education from Grades 1 to 11 or 6 to 11, and GCE Ordinary Levels.

Table 1. General information of the respondents.

\begin{tabular}{cccccccccc}
\hline & \multicolumn{3}{c}{ Teachers } & \multicolumn{3}{c}{ Parents } & \multicolumn{3}{c}{ Students } \\
\hline & $\mathbf{1 A B}$ & $\mathbf{1 C}$ & $\mathbf{T 2}$ & $\mathbf{1 A B}$ & $\mathbf{1 C}$ & $\mathbf{T 2}$ & $\mathbf{1 A B}$ & $\mathbf{1 C}$ & T2 \\
\hline Age & 45.5 & 45.4 & 50.2 & 46.5 & 46.5 & 47.5 & 16.7 & 15.4 & 15.1 \\
Female (\%) $_{\text {Income }}^{*}$ & 88.4 & 86.8 & 96.0 & 53.8 & 57.1 & 41.6 & 62.0 & 86.9 & 40.7 \\
Income $^{* *}$ & 243.01 & 249.21 & 219.43 & 260.09 & 212.39 & 70.43 & $\mathrm{~N} / \mathrm{A}$ & $\mathrm{N} / \mathrm{A}$ & $\mathrm{N} / \mathrm{A}$ \\
$\mathrm{N}$ & 1092.34 & 663.18 & 507.62 & 446.10 & 336.73 & 182.63 & $\mathrm{~N} / \mathrm{A}$ & $\mathrm{N} / \mathrm{A}$ & $\mathrm{N} / \mathrm{A}$ \\
\hline
\end{tabular}

Note: Average educational qualification of teachers was between Advanced Level A/L and graduate level. * represents respondents' average income level (US\$), while ** represents the average household income (US\$).

The average age of teachers and parents was between 45 and 50 years. Most were female. The individual average income of the teachers did not show any variation, but parents' average personal income varied in a broader range. It is worth noting that the average individual income of $1 \mathrm{AB}$ school parents was higher than that of $1 \mathrm{C}$ and $\mathrm{T} 2 \mathrm{school}$ parents. The average income of $1 \mathrm{AB}$ and $\mathrm{T} 2$ school parents was significantly different. The same was also true in the average household income category.

Table 2 shows the data of the attitudinal question of the teacher questionnaire, framed as "How often do you use ICT facilities for the TLP". The question was answered with a five-point Likert scale relating to the use of ICT facilities for the TLP. We repeated the same question in the parent questionnaire to triangulate the data, framed as "According to your knowledge, if an ICT facility is available, how often does your child use this facility for the TLP". In addition, the responses were linked with the household income: below USD 250, USD 500-1000, and above USD 1000. We also added educational level: below graduate level, graduate level, and above graduate level. 
Table 2. Attitudinal responses for Usage of ICT facilities for the TLP in the schools of the KEZ.

\begin{tabular}{ccc}
\hline & Teachers (\%) & Parents (\%) \\
\hline Never (\%) & 19.61 & 9.21 \\
Rarely (\%) & 29.41 & 13.16 \\
Sometimes (\%) & 32.35 & 52.63 \\
Often (\%) & 15.69 & 19.74 \\
All the time (\%) & 2.94 & 5.26 \\
Total Response & 102 & 76 \\
\hline
\end{tabular}

Out of 102 responses, about $49 \%$ of the teachers negatively responded to the attitudinal question of "How often do you use ICT facilities for the TLP" in the teacher questionnaire. Only $18 \%$ of the teachers responded positively, and $32 \%$ were uncertain. Out of 76 responses from parents, nearly $23 \%$ responded negatively, only $24 \%$ responded positively, and $52 \%$ were uncertain when given the attitudinal question "According to your knowledge, if ICT facilities were available, how often did your child use these facilities for the TLP" in the parent questionnaire (Table 3). Accordingly, parents' responses were more positive regarding the use of ICT facilities for the TLP. This also indicates that when the family income and educational level increases proportionally, the attitude towards the use of ICT is more positive among teachers and parents.

Table 3. Attitudinal responses for Use of ICT facilities for the TLP in the schools of the KEZ (income and education).

\begin{tabular}{|c|c|c|c|c|c|c|c|c|c|c|c|c|}
\hline \multirow{3}{*}{ Responses } & \multicolumn{6}{|c|}{ Income } & \multicolumn{6}{|c|}{ Education } \\
\hline & \multicolumn{3}{|c|}{ Teachers } & \multicolumn{3}{|c|}{ Parents } & \multicolumn{3}{|c|}{ Teachers } & \multicolumn{3}{|c|}{ Parents } \\
\hline & A & B & $\mathrm{C}$ & A & B & $\mathrm{C}$ & $<\mathrm{G}$ & G & $>G$ & $<\mathrm{AL}$ & AL & G \\
\hline Never & 66.7 & 40.9 & 13.3 & 5.9 & 15.0 & 0.0 & 8.1 & 31.6 & 22.2 & 31.4 & 8.0 & 11.1 \\
\hline Rarely & 0.0 & 13.6 & 33.3 & 11.8 & 10.0 & 0.0 & 35.1 & 23.7 & 16.7 & 5.7 & 20.0 & 16.7 \\
\hline Sometimes & 33.3 & 31.8 & 23.3 & 52.9 & 55.0 & 55.6 & 35.1 & 34.2 & 33.3 & 45.7 & 48.0 & 44.4 \\
\hline Often & 0.0 & 9.1 & 23.3 & 23.5 & 20.0 & 22.2 & 16.2 & 10.5 & 22.2 & 14.3 & 16.0 & 22.2 \\
\hline All the time & 0.0 & 4.6 & 6.7 & 5.9 & 0.0 & 22.2 & 5.4 & 0.0 & 5.6 & 2.9 & 8.0 & 5.6 \\
\hline Total & 3.0 & 22.0 & 30.0 & 17.0 & 20.0 & 9.0 & 37.0 & 38.0 & 18.0 & 35.0 & 25.0 & 18.0 \\
\hline
\end{tabular}

Note: A represents $\leq$ USD 250; B represents USD 500-1000; C represents $\geq$ USD 1000; <G represents below graduate level; G represents graduate level; $>\mathrm{G}$ represents postgraduate level; $<\mathrm{AL}$ represents below advanced level, and AL represents advanced level.

Figure 2 shows the required ICT literacy of teachers for the TLP $(1 \mathrm{AB}, 1 \mathrm{C}$, and T2 schools). ICT literacy is determined by considering three levels of ICT courses offered by the government for teachers in-service, at the teacher resource centers established in each educational zone in the country, and for pre-service teachers during their training period at teacher training colleges. These courses are optional. They include introductorylevel courses (ILC), elementary level courses (ELC), and advanced level courses (ALC). In addition, two levels of advanced ICT training, including special training for the use of ICT tools, interactive board laptops (SLC), and ICT for pedological purposes (ITL), were included in this study's classification. The distribution area of the chart is almost equal in each category of $1 \mathrm{AB}, 1 \mathrm{C}$, and $\mathrm{T} 2$ teachers. Most of the teachers of each type had engaged in ILC and ELC courses.

The $1 \mathrm{AB}$ teachers' distribution satisfactorily covered all the components of courses except ALC; more were distributed in the ITL and SLC training courses. ICT courses were engaged in by $1 \mathrm{C}$ teachers, with a distribution that showed more frequent engagement in ALC courses, which showed a poor response among $1 \mathrm{AB}$ schoolteachers. The T2 teachers' distribution was more frequent in the ELC courses, but showed a poor response to the ITL, SLC, and ALC courses. This indicates that teachers of all three categories of school had an equal, elementary knowledge of ICT, but such knowledge was not sufficient to overcome the challenges they faced when implementing ETLMs.

Additionally, it is evident that the COVID-19 pandemic has prompted a breakthrough in teacher education. The well-known thesis "the quality of teacher training determines 
the quality of school education" has acquired particular importance for teacher education in this extreme pandemic situation. Therefore, it is highly recommended that teachers be provided with more ICT advanced knowledge and competencies.

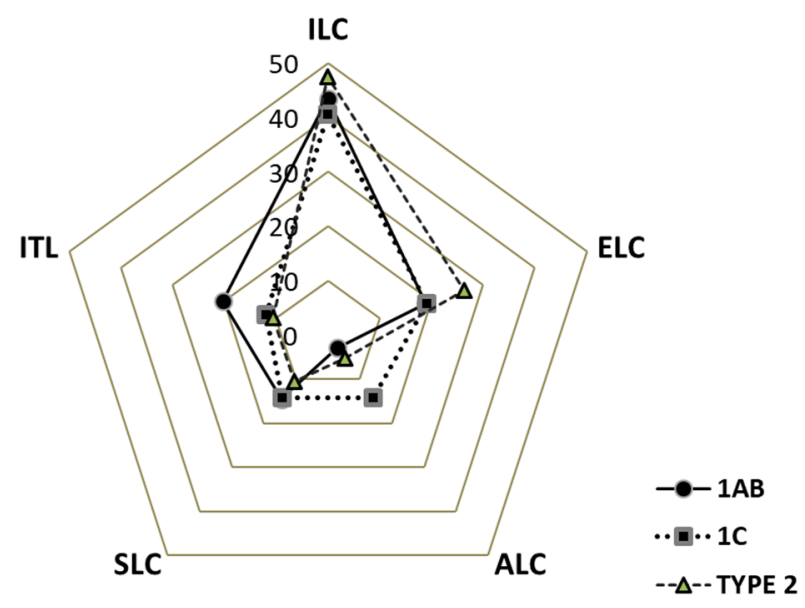

Figure 2. ICT knowledge of teachers (\%).

Figure 3 shows: A. Desktop/laptop computer availability at home (\%); B. Smartphone availability at home (\%); C. Wi-Fi/Internet availability at home (\%); D. Commencement of online programs (\%); E. Use of social media (\%), and F. Engagement with the online TLP $(\%)$. Charts A, B, and C show the computer appliance availability and the initial feasibility of commencing an online TLP at the domestic level. The data above clearly reveals a gap between $1 \mathrm{AB}, 1 \mathrm{C}$, and $\mathrm{T} 2$ schools, which was more significant between $1 \mathrm{AB}$ and $\mathrm{T} 2$ schools. Charts D, E, and F show the technical feasibility and the commencement of the online TLP. Charts D and F show the engagement with the online TLP initiated by the teachers, and the data were triangulated through the response of parents and students. According to Chart D, 1C teachers made a specific attempt to initiate an online TLP. The teachers' constraints when using this ETLM were mainly due to the lack of required appliances at home. The overall distribution of the data, which was similar to previous readings, signified a clear gap between $1 \mathrm{AB}$ and $\mathrm{T} 2$ schools. This can be expected to affect equal access to education.

Figure 4 shows the attitudinal response to the use of ICT in the TLP. The technology acceptance model (TAM), developed by Davis (1989) [19], was used to explain the determinants of computer acceptance and user behaviors across a broad range of computing technologies and populations. Two attitudinal questions were asked, with answers given on a five-point Likert scale (SA; strongly agree 1, A; Agree 2, U; uncertain 3 SD; strongly disagree 2 and D; disagree 1). Question 1, "According to my knowledge ICT is helpful for the TLP", was given in the teacher, parent, and student questionnaires.

Question 2 was: "According to my knowledge, ICT is not helpful to the TLP", and was included in the teacher and student questionnaires. The Likert-scale responses of the questions showed that over $80 \%$ of teachers, students, and parents attitudinally accepted the usefulness of ICT in the TLP. Chart F in Figure 2 shows that over $60 \%$ of the engagements in online education in the $1 \mathrm{AB}$ schools had a higher response for behavioral intention to ICT usage, predicting positive technology acceptance according to the Davis TAM Model [19] among the teachers, parents, and students. The attitudinal response towards ICT usage and its effect on the TLP indicates that the majority of respondents (i.e., students, teachers, and parents) believe that ICT use helps the TLP. Moreover, most respondents believed that ICT is important to the TLP, and reported being confident in using ICT for the TLP. Most of the variables in the Probit regression model were not significant. Therefore, we did not include the results in the analysis. The capacity for introducing a mobile phone device to the TLP in a physical classroom setting is referred to as "mobile learning" (M-learning) [20,21]. Due to their outstanding durability, most developed and developing countries are now attempting to incorporate smartphone use into the teaching-learning process from various 
perspectives [21,22]. Figure 5 displays the types of social media used by the parents, teachers, and students in the KEZ during the COVID-19 lockdown period, suggesting the widespread use of mobile phones among the teachers, parents, and students in the KEZ. As a result, the use of social media programs, such as Facebook, WhatsApp, Viber, and Zoom, was widespread among KEZ stakeholders, due to the absence of pre-methodologies or guidelines for implementing distance learning. Using the most available appliance for the task was therefore inevitable.
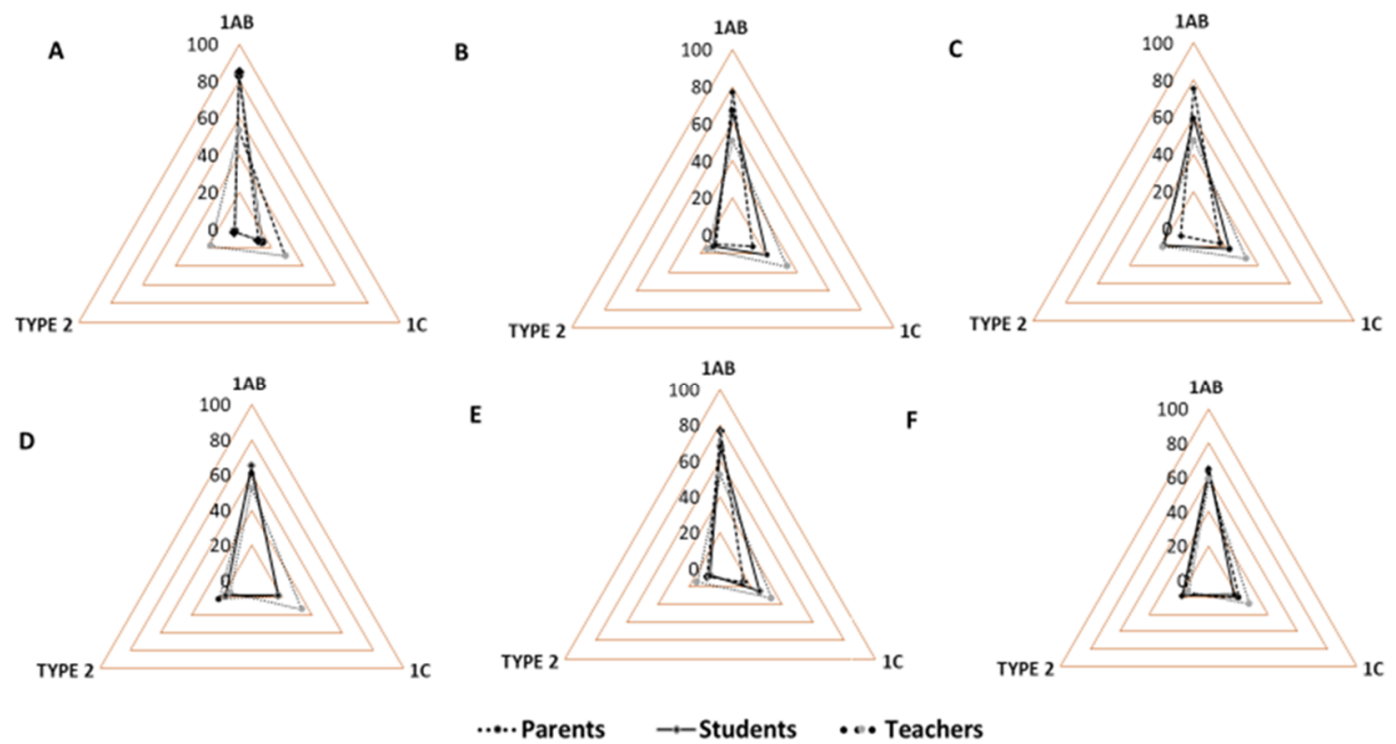

Figure 3. Use of computer appliances at the household level. Note: (A) Desktop/laptop computer availability at home (\%); (B) Smartphone availability at home (\%); (C) Wi-Fi/Internet availability at home (\%); (D) Commencement of online programs (\%); (E) Use of social media (\%), and (F) Engagement with the online TLP (\%).
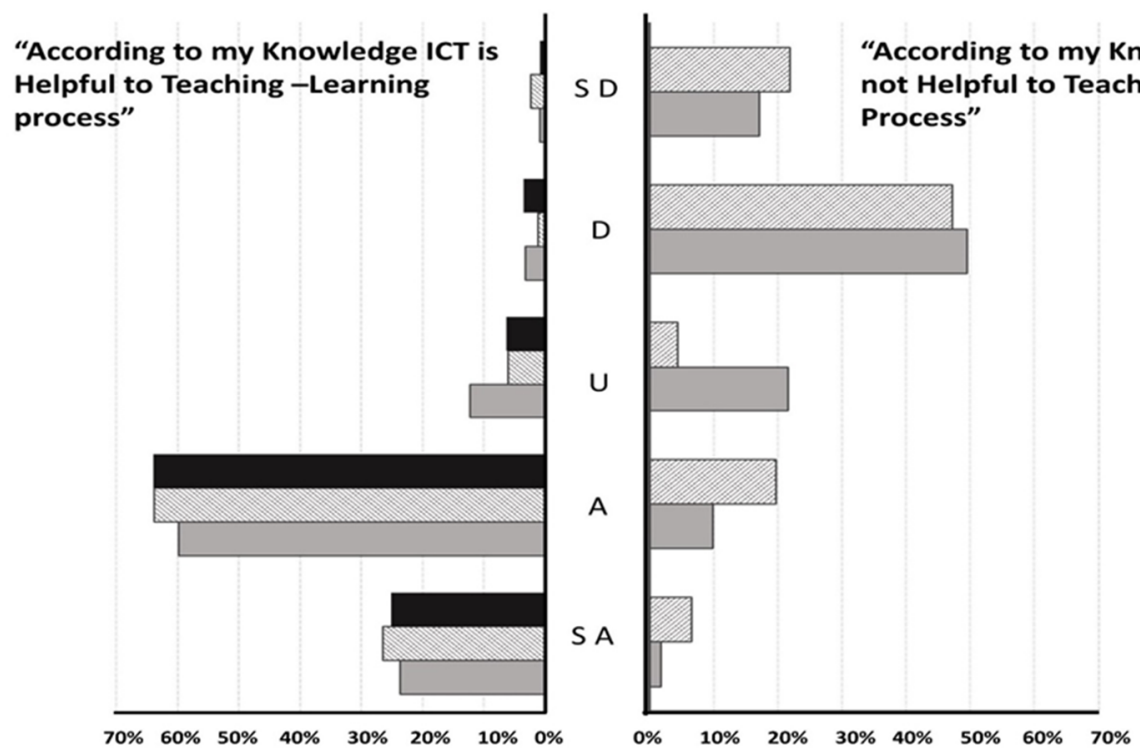

Figure 4. Attitudinal response regarding ICT usage and the TLP.

Figure 6 displays the emergency teaching-learning methods used by stakeholders in the KEZ during the COVID-19 pandemic lockdown period. Social media use showed a wider distribution among the stakeholders, at $64.70 \%$ by teachers, $59.90 \%$ by students, and $56.60 \%$ by parents. Hence, Figure 5 shows that the WhatsApp social media application had a wider use among the stakeholders, at $36.50 \%$ by teachers, $41.20 \%$ by students, and $36.10 \%$ 
by parents, and was dominant in the ELTM compared to the standard and traditional TLP. The durability of the application, particularly the offline accessibility, caused this high prevalence among the stakeholders. This study further revealed that mobile learning applications were more dominant in the KEZ than standard online applications.

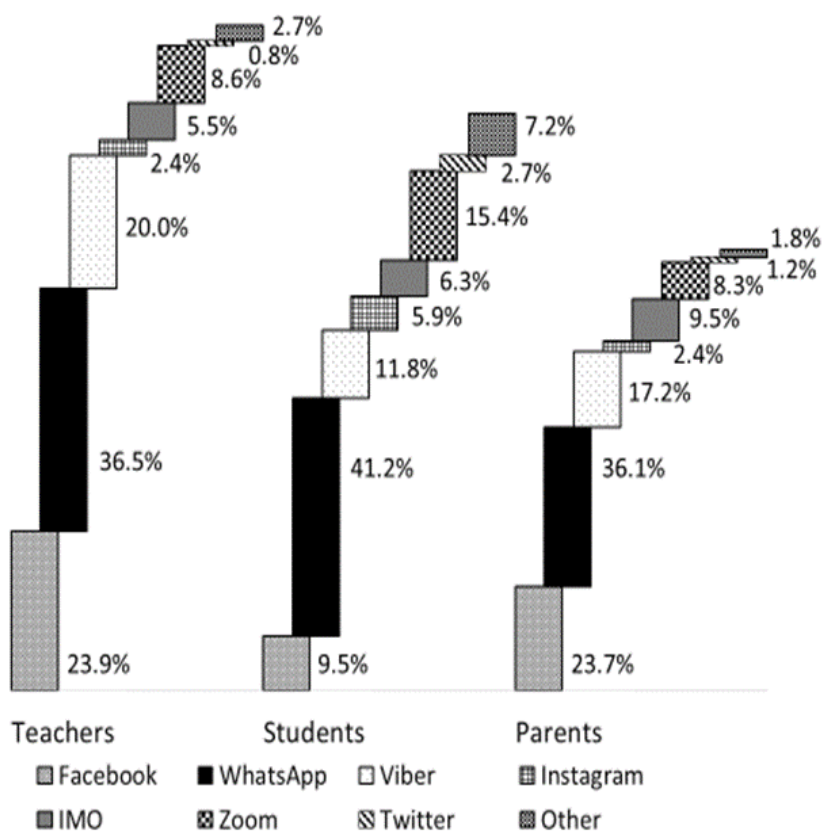

Figure 5. Types of social media used by stakeholders in the KEZ.
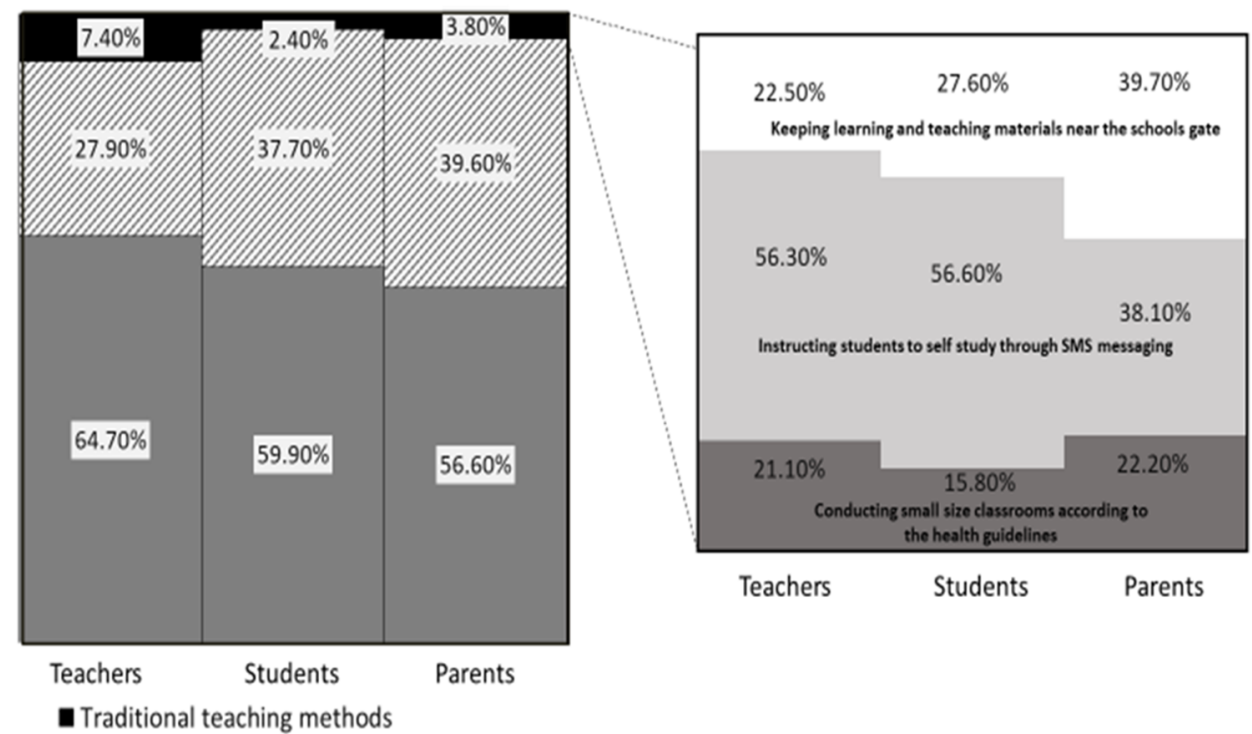

Q Standard online teaching platforms

using social media

Figure 6. The ELTMs implemented by the stakeholders of the KEZ.

WhatsApp is a free messenger application which is compatible with many platforms, including iPhones and android phones. Therefore, it is widely used by students to send multimedia messages, such as videos, photos, etc. Internet access is required to use WhatsApp. Information is able to be accessed in real-time through WhatsApp, and sharing such information through technology is both instant and convenient. WhatsApp messenger has many collaborative features. It allows the user to exchange videos, text messages, 
images, and voice notes. It supports the interaction of up to 50 group members, has an unlimited messaging facility, and uses a 3G/EDGE internet data plan or Wi-Fi to ensure continuous data transmission across platforms. In addition, it is compatible with different devices (smartphones, tablets, etc.), and has the ability to send different modes of messages (text messages, pictures, videos, voice notes) [23-25].

There is growing evidence that mobile applications such as WhatsApp have significant potential for the TLP and can significantly impact pedagogies, allowing direct access to rich online resources, and placing a greater emphasis on students' creativity, autonomy, and responsibility for their learning [26,27]. The preceding empirical evidence supports the KEZ stakeholders' decision to use WhatsApp for the TLP as an emergency solution. It also has a significant lead over traditional web platforms.

According to Figure 6, $7.40 \%$ of teachers, $2.40 \%$ of students, and $3.80 \%$ of parents confirmed that they engaged in the traditional TLP* during the COVID-19 pandemic lockdown period. It further elaborates on the types of traditional TLPs implemented by the stakeholders of the KEZ. Initially, three types of traditional TLPs were identified through the responses of the stakeholders. These included small-sized classrooms according to the health guidelines (SSCAHG), instructing students to self-study through SMS messaging (ISTSSM), and keeping learning materials near the school gate (KTLMSG).

In the KEZ, T2 schools generally implemented traditional methods (TTP). The SSCAHG method had a broader distribution in the graph, with teachers at $56.30 \%$, students at $56.60 \%$, and parents at $38.10 \%$. In this method, teachers instructed the students in self-studying through SMS messaging or a short telephone conversation directly to the students or the parents. Further messages were passed to the student community through student leaders. The SSCAHG method was initially used during the first lockdown for COVID-19, as an emergency precaution in the TLP. Later in the first lockdown, after the community had settled and was allowed to meet, the ISTSSM and KTLMSG procedures were employed as an extended form of the SSCAHG method. Students placed their activity documents near the school gate, and the teachers collected them at the school gate and corrected them. The KTLMSG method was mainly conducted and used by the KEZ teachers to cater to the assessment and evaluation requirements of the ETLM, by strictly adhering to the recommended sanitizing protocols given by the health authorities. Such practices were directly monitored by the principles of the schools, contrary to students placing their assessments near the school gate to submit to individual teachers. Once the teachers collected them, they marked the assessments and again put them at the gate. The entire process adhered to the health authorities' guidelines. In the KEZ, using KTLMSG procedures was a regular practice in all types of schools.

Figure 7 shows the teaching aids employed by KEZ teachers when applying ETLMs during the COVID-19 pandemic lockdown. Parents and students were asked the same question to triangulate the data. We identified eight types of teaching aids from the responses. They included: (1) posting handwritten documents (PHWD), (2) posting typeset documents (PTD), (3) posting voice cuts (PVC), (4) posting PowerPoint presentations (PPPT), (5) posting downloaded video clips (PDVC), (6) connecting live to teaching-learning platforms for irregular demonstrations (LCTLPR), (7) connecting live to teaching-learning platforms for daily demonstrations (LCTLPD), and (8) other methods as teaching aids (OTM).

The use of LCTLPD and OTM by teachers was minimal when compared to other TLP techniques. The PHWD method was more dominant than the PTD method because it was more convenient and durable through WhatsApp and other teaching-learning platforms. The PPPT and PDVC methods also had a wide distribution among the stakeholders, and were highly preferred. LCTLPR and LCTLPD were less commonly used, but showed some increase in use. The results also highlighted that teachers' lack of requisite ICT competency prevents them from using online platforms effectively. Teachers were very likely to post handwritten documents onto online platforms. Possibly, they believed that handwriting is more accessible than typing, because typesetting was complicated for them. The lack 
of basic ICT abilities, such as typesetting, is a serious obstacle to employing advanced interactive teaching aids in the TLP.

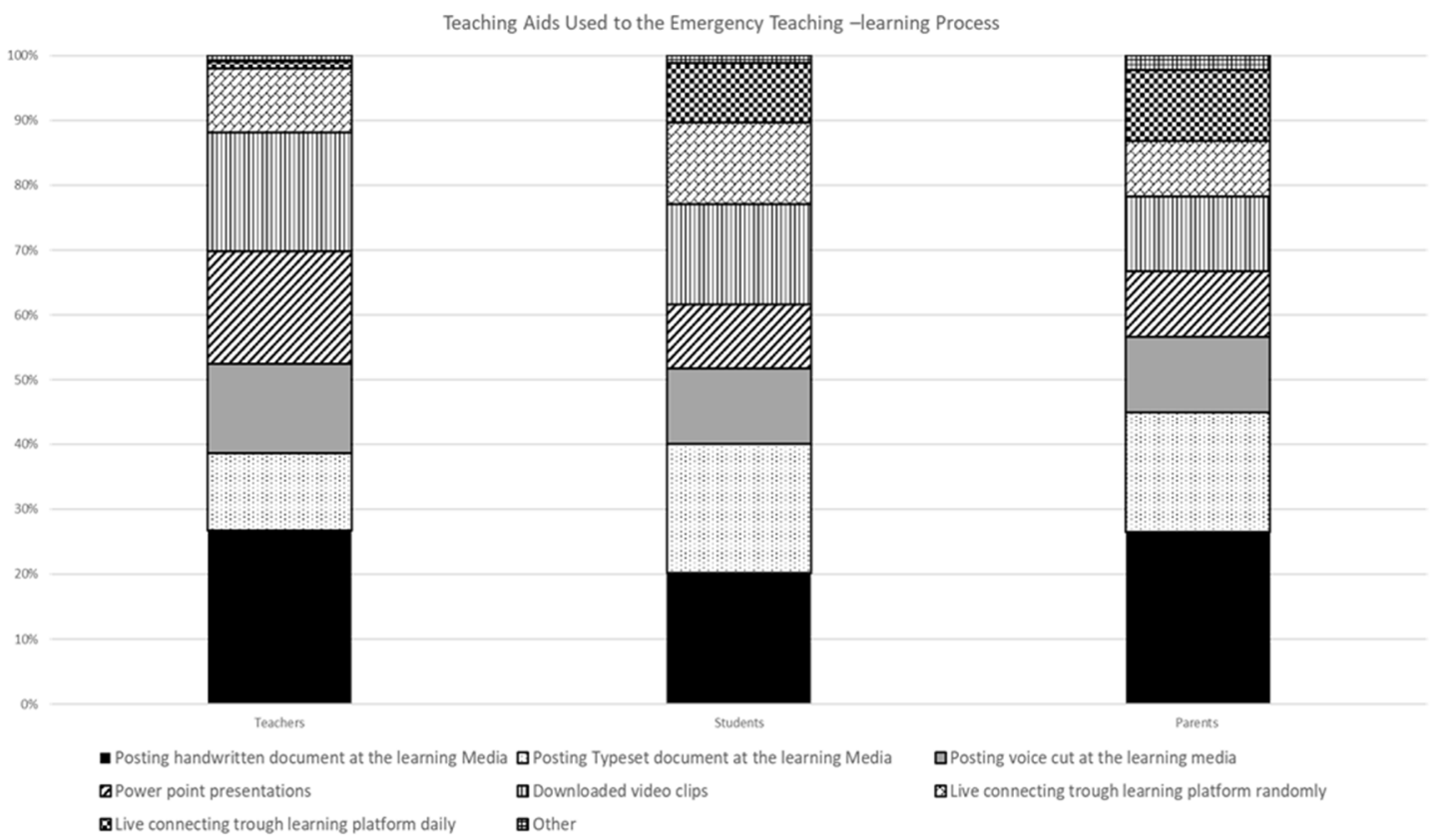

Figure 7. Teaching aids used by the stakeholders of the KEZ.

\section{Discussion}

\subsection{Present and Future Challenges of ETLMs}

As the second-largest city in Sri Lanka, Kandy houses a multi-religious and multiethnic population of 1.3 million within a land area of 26.45 square kilometers. The estimated transient population occupying Kandy per day is 500,000. In contrast, employment per day is 90,000 , and education per day is 60,000 . This area is one of the main contributors to the country's GDP [28]. Due to Kandy being the second largest city, the findings of this study give us the maximum scenario or best possible performance when implementing ETLMs in Sri Lanka. Therefore, in other parts of the country, the situation may be worse in terms of implementing ETLM.

Further, in a survey conducted in 2018 by DCS, only $52 \%$ of Sri Lankan households with school-aged children owned a smartphone or computer (laptops $52 \%$, desktop 10\%, tablets 3\%), which are essential for online learning. Only $40 \%$ had an internet connection, primarily via mobile phones (mobile phone dongles $37 \%$, Fiber/ADSL/Wireless $4 \%$ ). This survey projected the reality of the availability of computer-related appliances in household settings in Sri Lanka [29]. Accordingly, less than half of the households in Sri Lanka can engage in online education via distance in an emergency. It is an accepted norm that the traditional classroom settings of schools, despite many disparities, cater to all students through a common equitable platform, irrespective of their different cultural or socioeconomic backgrounds, ensuring the co-values of free education. Naturally, however, the online TLP excludes students who do not have the necessary equipment to engage in such programs. In this context, the accessibility of free education in the country is at an alarming stage. Purchasing the required appliances for ETLMs may be challenging for both students and teachers. Therefore, assessing blended education in the post-COVID world may create more disparities in terms of free education. Developing countries such as Sri Lanka may face many challenges. 


\subsection{Policy Recommendations}

The COVID-19 pandemic has given rise to a large scale of pedological experimental work. These experimental frameworks include remote learning using digital educational environments backed by distance learning technologies, a new approach within the education fraternity. The extreme situation created by the pandemic has turned out to be a litmus paper for identifying constraints and pressure points of distance education [30]. Therefore, ETLMs via distance have to be systemized and streamlined according to the core values of pedagogy, through policy settings [31]. In the Sri Lankan context, online applications were at a primitive stage. The experience of fully online education for both teachers and students was minimal compared to developed countries. Such experiences were limited to university-level education. Therefore, both in-service and pre-service programs need to be modernized and include more digital pedagogy, to respond to the post-COVID-19 demand for online education settings to provide a blended educational experience to the students of the country. The future of education is likely to be balanced education, combining traditional learning and online learning methodologies. More frequently, teachers and students may choose the best way to teach or learn the given content of a subject. It is necessary to prepare students and teachers to use digital technologies, including in combination with online learning, and to teach them to determine which lessons are more effective to conduct in the classroom or remotely, and what additional resources should be given to each topic studied. Therefore, in policy settings, in-service and pre-service training programs must be modernized and authenticated to empower teachers to meet the above challenges. On the other hand, the government should create an online and offline database to share and impart knowledge to teachers and students in the free access domain. To achieve the above targets, the government should allocate the necessary capital and recurrent expenditure to provide digital appliances to marginalized groups, and establish a standardized framework to implement holistic education through blended education in the post-COVID-19 world.

\section{Conclusions}

This study found that there are visible disparities among privileged and non-privileged schools in the urban settings of the KEZ. In this case, the 1AB category of schools were privileged, and the T2 category of schools were non-privileged. The teachers, principals, and administrators are appointed and regulated by the KEZ to the respective schools. According to the survey results, a gap existed between the privileged and non-privileged schools in the KEZ when implementing ELTMs. At the same time, online teaching was satisfactory, according to the stakeholders' attitudes. The results revealed that mobile teaching and learning through social media was significantly preferred to standard online platforms. Accordingly, the "WhatsApp" messaging app had a high acceptance among the stakeholders of the KEZ. Innovative teaching and learning approaches were evident in the mobile TLP, lesson instruction over the phone or SMS, and posting handwritten documents on social media during the implementation of ELTMs. However, overall, lesson delivery online was at a problematic stage compared to traditional classroom teaching in terms of assessment and evaluation. There are no positive disparities among teachers incomes or qualification levels at these schools. When examining the average income levels of the parents at the schools, there was however a positive gap among the $1 \mathrm{AB}$ and $\mathrm{T} 2$ categories. Students from underprivileged settings were polarized into the T2 category of schools in the KEZ. This could be the reason for the gap created when implementing ELTMs among privileged and non-privileged school settings in the KEZ. This gap may be more significant between urban and rural settings. Therefore, future research should consider examining the overall challenge of online distance teaching-learning adaptation as an ETLM, comparing urban and rural settings. This study proposes that the digital divide and the nature of stakeholder technology adoption in online distance learning as an ETLM should be evaluated in the country's education decision-making process. 
Author Contributions: Conceptualization, R.G, M.K., W.A. and S.S.; methodology, R.G. and W.A.; formal analysis, R.G. and S.S.; writing-original draft preparation, R.G., M.K., W.A. and S.S.; review and editing, R.G., S.S. and P.E.; visualization, S.S. and R.G. All authors have read and agreed to the published version of the manuscript.

Funding: This research received no external funding.

Institutional Review Board Statement: Not applicable.

Informed Consent Statement: Not applicable.

Conflicts of Interest: The authors declare no conflict of interest.

\section{References}

1. UNESCO. 2013 EFA GMR Teaching and learning for development_overview. Glob. Monit. Rep. 2013, 1, 1-6.

2. Kelegama, S. Development in Independent Sri Lanka: What Went Wrong? Econ. Polit. Wkly. 2000, 35, 1477-1490.

3. Ministry of Education Sri Lanka. Educati on First Sri Lanka Ministry of Educati on Sri Lanka; Ministry of Education Sri Lanka: Battaramulla, Sri Lanka, 2013; pp. 11-20. ISBN 9789552800412.

4. Alawattegam, K.K. Free Education Policy and its Emerging Challenges in Sri Lanka. Eur. J. Educ. Sci. 2020, 7, 1-14. [CrossRef]

5. Wayne, D.B.; Green, M.; Neilson, E.G. Medical education in the time of COVID-19. Sci. Adv. 2020, 6. [CrossRef] [PubMed]

6. Hayashi, R.; Garcia, M.; Maddawin, A.; Hewagamage, K.P. Online-Learning-Sri-Lanka-During-Covid-19; Asian Development Bank: Manila, Philippines, 2020.

7. Williams, P.; Nicholas, D.; Gunter, B. E-learning: What the literature tells us about distance education: An overview. Aslib Proc. 2005, 57, 109-122. [CrossRef]

8. Bjorvatn, K.; Cappelen, A.W.; Sekei, L.H.; Sørensen, E.; Tungodden, B. Teaching through television: Experimental evidence on entrepreneurship education in Tanzania. Manag. Sci. 2020, 66, 2308-2325. [CrossRef]

9. Li, T.W.; Karahalios, K.; Sundaram, H. It's all about conversation. Proc. ACM Hum. Comput. Interact. 2021, 4, 1-37. [CrossRef]

10. Ertmer, P.A. Addressing first- and second-order barriers to change: Strategies for technology integration. Educ. Technol. Res. Dev. 1999, 47, 47-61. [CrossRef]

11. Swan, K.; Shea, P.; Fredericksen, E.; Pickett, A.; Pelz, W.; Maher, G. Building knowledge building communities: Consistency, contact and communication in the virtual classroom. J. Educ. Comput. Res. 2000, 23, 359-383. [CrossRef]

12. OECD. Strengthening Online Learning When Schools Are Closed-The Role of Families and Teachers in Supporting Students During the COVID-19 Crisis; OECD: Paris, France, 2020; pp. 1-14.

13. Serdyukov, P. Innovation in education: What works, what doesn't, and what to do about it? J. Res. Innov. Teach. Learn. 2017, 10, 4-33. [CrossRef]

14. Pokhrel, S.; Chhetri, R. A Literature Review on Impact of COVID-19 Pandemic on Teaching and Learning. High. Educ. Future 2021, 8, 133-141. [CrossRef]

15. Pelgrum, W.J. Obstacles to the integration of ICT in education: Results from a worldwide educational assessment. Comput. Educ. 2001, 37, 163-178. [CrossRef]

16. Gunawardana, K.D. Current Status of Information Technology And Its Issues in Sri Lanka. Int. J. Comput. Internet Manag. 2007, 15, 1-25.

17. Abeysekera, R. Success of E-Sri Lanka in Rural Ict Development : A Study of E-Nenasala Telecenters in Rathnapura District; Department of Education: Colombo, Sri Lanka, 2020.

18. Braesemann, F.; Lehdonvirta, V.; Kässi, O. ICTs and the urban-rural divide: Can online labour platforms bridge the gap? Inf. Commun. Soc. 2020, 1-21. [CrossRef]

19. Ma, Q.; Liu, L. The Technology Acceptance Model. Adv. Top. End User Comput. 2011, 4. [CrossRef]

20. Altaany, F.H. Usage whatsapp application for e-learning and its impact on academic performance in irbid national university in Jordan. Int. J. Appl. Eng. Res. 2015, 10, 39875-39879.

21. Lindsay, L. Transformation of teacher practice using mobile technology with one-to-one classes: M-learning pedagogical approaches. Br. J. Educ. Technol. 2016, 47, 883-892. [CrossRef]

22. Saikat, S.; Dhillon, J.S.; Wan Ahmad, W.F.; Jamaluddin, R.A. A Systematic Review of the Benefits and Challenges of Mobile Learning during the COVID-19 Pandemic. Educ. Sci. 2021, 11, 459. [CrossRef]

23. Dahdal, S. Using the WhatsApp Social Media Application for Active Learning. J. Educ. Technol. Syst. 2020, 49, 239-249. [CrossRef]

24. Kopecký, K.; Fernández-Martín, F.-D.; Szotkowski, R.; Gómez-García, G.; Mikulcová, K. Behaviour of Children and Adolescents and the Use of Mobile Phones in Primary Schools in the Czech Republic. Int. J. Environ. Res. Public Health 2021, 18, 8352. [CrossRef]

25. Cetinkaya, L. The impact of whatsapp use on success in education process. Int. Rev. Res. Open Distance Learn. 2017, 18, 59-74. [CrossRef]

26. Gon, S.; Rawekar, A. Effectivity of E-Learning through Whatsapp as a Teaching Learning Tool. MVP J. Med. Sci. 2017, 4, 19. [CrossRef]

27. Mtega, W.P. Using WhatsApp Messenger for improving learners' engagement in teaching and learning: A case of undergraduate students at the Sokoine University of Agriculture, Tanzania. Libr. Philos. Pract. 2021, 2021, 1-19.

28. Urban Development Authority. Town Development Plan. Volume-I 2009-2030; Urban Development Authority: Colombo, Sri Lanka, 2009. 
29. Department of Census and Statistics of Sri Lanka. Household Income and Expenditure Survey 2016 Final Report; Department of Census and Statistics of Sri Lanka: Colombo, Sri Lanka, 2018; ISBN 9789557020549.

30. Valeeva, R.; Kalimullin, A. Adapting or changing: The covid-19 pandemic and teacher education in Russia. Educ. Sci. 2021, 11, 408. [CrossRef]

31. Bond, M. Schools and emergency remote education during the COVID-19 pandemic: A living rapid systematic review. Asian J. Distance Educ. 2021, 15, 191-247. [CrossRef] 